Krzysztof Wawrzonkowski

Nicolaus Copernicus University, Toruń, Poland

ORCID: 0000-0003-2792-1312

e-mail: kwawrzonkowski@umk.pl

\title{
On Archibald Alison's Conception of Aesthetic Experience and Its Selected Sources and Inspirations
}

They walked along a narrow path which formed the limit of two woods: to the right oaks and beeches grew, to the left were pinetrees. Mrs Wąsowska's red bodice gleamed between the pines from time to time, or the white veil of Ewelina could be seen. At one point the path forked, and Wokulski wished to turn aside, but Izabela prevented him: 'No, no,' she said, 'don't let's go that way, for we shall lose sight of the others, and the woods are only attractive to me when there are other people about. At this moment, for instance, I can understand them... Just look... Isn't that part like a huge church? The rows of pines are columns, there's a side nave, and there the great altar. Just look! Now the sun between the boughs looks like a Gothic window. What an extraordinary variety of sights! There you have a lady's boudoir, and those low bushes are her dressing-table. There's even a mirror, which yesterday's rain left behind. And this is a street, isn't it? Rather crooked, but a street all the same... And yonder is a market-place or square. Do you see it all?' 'I do, when you point it out,' Wokulski replied with a smile, 'but one needs a very poetic imagination to see the resemblances.' 'Really? Yet I've always thought myself the embodiment of prose.' 'Perhaps because you haven't yet had an opportunity to discover all your capabilities,' Wokulski replied, displeased because Felicja was approaching. 


\section{The sources of Alison's associationism: Hume's guidelines}

When in 1757 David Hume (1711-1776) published Of the Standard of Taste, it seemed that he lost the opportunity to use the associative relations of imagination to explain precisely the nature of aesthetic experience. These relations, introduced in A Treatise of Human Nature as the most important mechanisms of the functioning of this power, became the basic way of explaining the course of cognitive processes, as well as a specific reconstruction of what passed and an anticipation of what is to come. At the same time, they allowed us to understand how complex ideas arise, how emotions accumulate, or how sensory perceptions are emotionally coloured. In fact, we should say that imagination, which plays one of the main roles in Hume's philosophy, together with its associative relations, enables man to construct a widely understood image of the world and to find his bearings within it. It gives us the ability to accumulate perceptual content, but also the chance to view how it plays its roles on a theatre stage, as the mind is defined here. Pointing out the connections between them, as well as the mechanisms that govern the emergence of emotions, the way they are manifested and the way they drive man to action, was for Hume equivalent to the discoveries of natural philosophy of his day. In his eyes they operated, or were in force, in an equal manner. So why not use associative relationships to describe a specific kind of experience, such as aesthetic experience? Why were they not explicitly applied in the essay mentioned above? Could it be that the individual character of particular associations made it impossible to achieve the goal so outlined and provided a basis for expressing only individual tastes?

In discussing the most important elements of Hume's conception of aesthetics, I will attempt to address these questions, and then see if Alexander Gerard (1728-1795) draws conclusions from his teachings. Undoubtedly, it is he who takes over Hume's thought and links it with the aesthetic theory by Archibald Alison (1757-1839). Recognizing the rise of interest in associationism at the time, he tries to use it to explain some of the mechanisms responsible for arousing the emotions that are relevant for beauty, sublimity, and the other aesthetic categories he distinguished. And it is Gerard who develops the conceptions of associating ideas and accumulating particular emotions, and the exercise of imagination resulting in experiencing peculiarly aesthetic experiences. We find these conceptions almost fully developed in Alison's essays. Last but not least, it is in the work of each of the philosophers mentioned above that we see a gradual increase in interest in using associative relations to define the nature of aesthetic experience, and this at a time when aestheticians, 
such as Edmund Burke (1729-1797), were questioning the value of such a proposal. Therefore, in this paper I will indicate the sources of Alison's views on the nature of aesthetic experience, and reconstruct them in terms of its course, conditions, and characteristic properties of interest. I will also demonstrate how they were innovative in relation to his predecessors and in terms of the originality of thought.

In the Treatise, Hume explains beauty in two ways. In both cases he does this by referring to the emotions that constitute them. In one of the distinctions he adopted, emotions can be viewed as direct and indirect. The former are a kind of sensory experience like joy, annoyance, or pain and can occur even when no one is around. The latter are characterized by mediation in the presence of others, which means that without the participation of third parties, they cannot actually be voiced. It is within these feelings that Hume makes a further distinction between calm and violent emotions. Each of them becomes the basis for distinguishing a unique kind of beauty. Among gentle emotions we find "the sense of beauty and deformity in action, composition, and external objects." 1 Thus, these emotions turn out to be the basis for experiencing the broadly understood beauty or ugliness of the world of phenomena, and with them the sheer values of human behavior and actions. Such an extension of a quite common aesthetic experience is a consequence of the affinity of Hume's views with the philosophy of such theoreticians of taste and proponents of moral sense theory as Shaftesbury (1671-1713) and Francis Hutcheson (1694-1746), for whom the marriage of ethics and aesthetics is in principle something natural. In Hume this theme is not so obvious, for although he repeatedly stresses that perhaps our emotion of beauty is a reaction to the perception of a certain form of objects, he does not decide whether this is due to the natural constitution of our mind or to the intervention of some higher authority. The former view was certainly closer to him. Both cases can be described as interventionist aesthetic divinism, as opposed to the teleological divinism proper to the two philosophers mentioned above. ${ }^{2}$

1 David Hume, A Treatise of Human Nature, reprinted from the original edition in three volumes and edited, with an analytical index, by L. A. Selby-Bigge (Oxford: The Clarendon Press, 1896), 276.

2 For in both we are dealing with a kind of intervention of a higher being that determines the relation between the emotion and the form of the object. Teleological divinism, on the other hand, assumes that beauty is synonymous with the perfection of the world artistically shaped by the Creator. Both terms are introduced and used by S. Morawski. With regard to Alison's aesthetics, he says: "The divinist tendency manifests itself in Alison's considerations in a twofold way: in the suggestions that relate to the constitution of our nature, which, 
On the grounds of the empiricism he adopted, however, it is not possible to decide whether any of the above propositions is true. Therefore, the final solution to this issue is not to be found in the Treatise, and the most clearly formulated thesis, still based on probability or mere conjecture, is to be found in Of the Standard of Taste, an essay whose nature, both popularizing and devoid of claims to a definitive solution of this important problem, allows such speculations. Hume thus leaves us in doubt as to the ultimate possibility of explaining the nature of aesthetic experience by associative relations, yet without being able to deal with the problem in any other way.

Within the framework of beauty, understood as a special kind of feeling of pleasure that comes from the perception of objects, we cannot but acknowledge that this feeling has a natural character. Beauty itself, on the other hand, acquires individual features and is conditioned by the viewer's personal experience, including his knowledge, associations, and tastes. Nor is there any possibility here of an aesthetic judgement that enjoys universal recognition or even the possibility of a dispute. Beauty so conceived is thus not even intersubjective. It just makes us happy.

The case is slightly different with beauty grounded in violent emotions. This is because an emotional resonance appears here, making it possible to compare one's own experiences with those of others. For this to happen, however, the experience of beauty must be mediated by the emotion of pride, which in turn must be subordinated to a concrete communicable notion of utility. Only thus do intersubjective judgements about beauty conceived as utility become at all possible. And we can enjoy the satisfaction of seeing that a useful object that we own is appreciated by others. The beauty of a fast carriage, a manoeuvrable canoe, or a spacious living room depends, therefore, on whether others perceive their usefulness and the relationship of ownership that exists between these objects and the object of pride, which is our self. In fact, beauty understood in this way is based on our need to compare ourselves with others and to see ourselves in their eyes, thus partly also on our vanity, thus fitting in well with the intensely developing sociability. But is this the kind of beauty that deserves any recognition? That is a separate issue.

To explain the two accounts of beauty articulated in the Treatise, however, Hume does not use the associative relations of the imagination,

through Providence, responds to certain object properties, and in the remarks on the ultimate work of the Creator, who formed the soul and the mind in such a way that it efficiently binds imagination, thought, and emotion into chains of association, see Stefan Morawski, Studia z historii myśli estetycznej XVIII i XIX w. (Warszawa: PWN, 1961), 87. 
although in the case of the former such a role can certainly be pointed to, at least to some extent, but Hume does not develop these threads. Some hints concerning this issue can be found in An Enquiry Concerning Human Understanding, whose task was to popularize selected aspects of the Treatise, rather than develop the concepts contained therein. But these are, according to Hume, only loose hints placed in a footnote. They mainly refer to the relations between ideas, the accumulation of emotions, and instructions for authors to base the plot of their works on associative relations, without which their works will not evoke the intended emotions, and these emotions will not be transferred from one character or object to another. Interestingly, they were not included in the last edition of R, personally prepared by Hume. They are to be found only in editions $\mathrm{E}$ to $Q$, which means that not all published versions of An Inquiry contain them, and therefore I take the liberty of quoting them in a slightly more extensive form:

It is evident, that in a just composition, all the affections excited by the different events described and represented, add mutual force to each other; and that, while the heroes are all engaged in one common scene, and each action is strongly connected with the whole, the concern is continually awake, and the passions make an easy transition from one object to another. The strong connection of the events, as it facilitates the passage of the thought or imagination, from one to another, facilitates also the transfusion of the passions, and preserves the affection still in the same channel and direction. Our sympathy and concern for Eve prepares the way for a like sympathy with Adam: The affection is preserved almost entire in the transition; and the mind seizes immediately the new object, as strongly related to that which formerly engaged its attention. But were the poet to make a total digression from his subject, and introduce a new actor, no way connected with the personages, the imagination, feeling a breach in the transition, would enter coldly into the new scene; would kindle by slow degrees; and in returning to the main subject of the poem, would pass, as it were, upon foreign ground, and have its concern to excite anew, in order to take party with the principal actors. [...] The same rule takes place in dramatic poetry; nor is it ever permitted in a regular composition, to introduce an actor who has no connection, or but a small one, with the principal personages of the fable. The spectator's concern must not be diverted by any scenes disjoined and separate from the rest. This breaks the course of the passions, and prevents that communication of the several emotions, by which one scene adds force to another, and transfuses the pity and terror it excites upon each succeeding scene, until the whole produces that rapidity of movement, which is peculiar to the theatre. How must it extinguish this warmth of affection to be entertained, on a sudden, with a new action and new personages, no way related to the former; to find so sensible a breach or vacuity in the course of the passions, by means of this breach in the connection of ideas; and instead of carrying the sympathy of 
one scene into the following, to be obliged every moment, to excite a new concern, and take party in a new scene of action? [...] These loose hints I have thrown together, in order to excite the curiosity of philosophers, and beget a suspicion at least if not a full persuasion, that this subject is very copious, and that many operations of the human mind depend on the connection or association of ideas, which is here explained. Particularly, the sympathy betwixt the passions and imagination, will, perhaps, appear remarkable; while we observe that the affections, excited by one object, pass easily to another connected with it; but transfuse themselves with difficulty, or not at all, along different objects, which have no manner of connection together. By introducing into any composition, personages and actions foreign to each other, an injudicious author loses that communication of emotions, by which alone he can interest the heart, and raise the passions to their proper height and period. The full explication of this principle and all its consequences, would lead us into reasonings too profound and too copious for these Essays. It is sufficient for us, at present, to have established this conclusion, that the three connecting principles of all ideas, are the relations of resemblance, contiguity, and causation. ${ }^{3}$

The comments proposed by Hume actually do not require to be additionally explained, as they explicitly demonstrate the philosopher's views. In addition, he himself argues that they should only be developed on the basis of thorough research into the detailed applications of associative relations within aesthetics perceived in the broadest sense. He does not do that anywhere, though. On the other hand, these passages, although eventually removed from the text, despite their evident conformity with what he had to say about emotions in the Treatise, remain the only trace of Hume's consideration of the aforementioned possibility of putting these relations into use. The trace is all the more important from the perspective of the present article, since Hume apparently refers here to the transfer of emotions towards one object to another associated with it, and the responsibility for this lies with the associations in question. This kind of emotional transference is found in both Gerard and Alison.

Finally, let us move on to Of the Standard of Taste, which, unfortunately, does not clearly explain the role of associationism in aesthetics either. It does, however, allow some important conclusions to be drawn with a considerable degree of probability. In addition to clearly defining beauty as an emotion, and stating that it appears differently to everyone

3 David Hume, "An Inquiry Concerning Human Understanding", in: David Hume, The Philosophical Works of David Hume. Including All the Essays, and Exhibiting the More Important Alterations and Corrections in the Successive Editions Published by the Author, in Four Volumes (Boston: Little, Brown and Company; Edinburgh: Adam and Charles Black, 1854), Vol. 4, 26-29. 
and is experienced differently by everyone, we find here a lot of information about imagination and its role in aesthetic experience. The initial commonsensical thesis about the individual and relative character of the emotion of beauty is complemented step by step by the statement that only developed taste makes it possible to recognize beauty correctly, and thus to experience it fully. Thus, Hume's emotivist philosophy, while leading to the subjectivity of experiences on the grounds of aesthetics, does not result in their relativization. The sensitivity of imagination, the original predispositions of the mind, our momentary disposition and acquired knowledge (also of human nature), are not without influence on experiencing beauty. The naturalness of the reaction to beauty, inevitably lost as a result of everyday experiences, habits, or even a preoccupation with existentially more urgent matters than the admiration of beauty, can be regained, or at least the adequacy of experiences related to it restored. However, it is a matter of developing oneself, acquiring certain knowledge, dealing with various beautiful objects, comparing them and becoming skilled in making aesthetic emotional judgements of taste. The sensitivity of imagination, which increases with subsequent experiences and the accumulating perceptual material, manifests itself in the rapid passage of the mind from one idea to another, in the tracking of connections between them, in catching the tiniest elements of a work of art, their connections with the whole and with the intention of the creator. Careful observation of oneself, of the activity of one's imagination, of one's personal tastes, emotions and passions, of one's associations, or, last but not least, an awareness of the present quality of one's taste, allows one to perfect the judgement of beauty. Apparently, while undeveloped taste is not subject to any rules and cannot be argued with, developed taste leads to a consensus among those who make judgements on the value of works of art. And this is not merely due to the fact that we refer precisely to the works to which Of the Standard of Taste is essentially devoted, but to the excellence of the tool, which is a taste supported by a sensitive imagination, a disinterested attitude, and a thorough study of the subject being judged. If there are doubts as to the value of our judgements, there will always be the support of fair critics and the standard of taste.

So what about associative relations? Implicitly, they are present almost everywhere here, explicitly, they are not mentioned at all. Their action enables us to construct our experience of the world as we know it and our emotional responses to it. Our whole experience is in fact supported by them, so they are indispensable in the aesthetic experience as well. They are also the basis of our knowledge of human nature and its various manifestations. Thus, by interacting with the work, we will not only expe- 
rience it, but also guess how others should perceive it, what emotions it will evoke in them, and what judgements of taste it will lead them to. The role of the associative relations of imagination in aesthetic experience will thus be the same as in ordinary experience. It makes it possible to capture an object in various relations with other objects, and enables a play of emotions associated both with it and with their perception. That is the end of it. Hume does not go any further; the role of association that interests is not commented on. Nor is it explicitly emphasized anywhere. None of the associative relations will be singled out here and charged with the responsibility for arousing certain emotions, for transferring them from one object to another, or even for intensifying their experience. There is no trace of the clues from An Inquiry here. Were they too laconic? And shouldn't we rather think that Hume paved the way for associationism in aesthetics, but did not use it himself? Certainly Gerard saw more potential in this and made more use out of associationism.

\section{Gerard's coalescence of ideas and accumulation of emotions}

What emerges from Gerard's writings on aesthetics is a picture of a thinker who pays great attention to the meticulousness of his descriptions and explanations of the various aspects of what we call aesthetic experience. Even his remarks in the extended third edition of An Essay on Taste, in which the Hume's standard of taste is subjected to rather severe criticism, testify to his meticulousness and greater research sensibility in this matter than that displayed by his great predecessor. It is therefore not surprising that his descriptions of taste and genius, as well as aesthetic categories, are so detailed and draw attention to various aspects of their manifestation in the human world.

Aesthetic experience in Gerard's view consists primarily of specifically related and cooperating internal senses, general sensitivity of imagination, developed taste supported by judgement, and sensitivity of the heart. Let me discuss in a nutshell each of these elements so that we can capture the influence of Gerard's views on Alison more clearly, and look at the differences between their theories in this respect.

The inner or reflective senses, or simply detailed tastes as they might be expressed, are natural human faculties upon which aesthetic taste is founded. They cannot be reduced to any sensory organs, and describing them as internal, in spite of perfectly knowing the writings of the proponents of the inner sense like Shaftesbury, Hutcheson, or Hume, is only 
metaphorical. In essence, it is about emphasizing the immediacy of action and the immediacy of the perception of objects. In addition, not in a way that is analogous to the senses. This means that each sense has its own kind of perception, but in relation to whole aggregates of qualities, that is, to individual objects as such, or as part of a fine-tuned whole, such as harmony. By the same token, these senses should be described, like taste and genius, as derivatives of imagination, its principles, or sensitivity to a certain kind of stimuli. Among them Gerard includes the senses of beauty, sublimity, novelty, imitation, harmony, ridicule, and virtue. Each of the above captures its proper phenomenon and supports the others in their work. By complementing and tuning each other, they are able to achieve perfection, which directly translates into the quality of the taste proper. In experiencing any kind of object, the involvement of each of the senses causes their proper emotions to accumulate and unite into one guiding feeling. And just as the predominance of one of the senses will give the final touch to aesthetic taste, so the perceived objects will appear to him through the prism of one guiding characteristic that dominates over the others, which determines their general or resultant value. Hence the postulate to develop all the senses, so that taste may acquire its proper scope and perfection.

By singling out the inner senses, Gerard tries to give us an account of the complexity of aesthetic experience, the variety of which can be explained by a different scope of development, each of them individually, and as a jointly acting whole. ${ }^{4}$ At the same time, he notes that the feelings that flow from the movement of one of them are combined with the emotions inherent in the others:

Our sentiments and emotions receive an immense addition of strength from their reciprocal influence on one another. Concomitant emotions, related by their feeling, their direction, or their objects, or even without any relation existing in the mind together, run into one, and by their mixture produce an intense sensation. Hence different gratifications, either of the same or diverse senses, occurring to the mind at once, give it a complicated joy. ${ }^{5}$

4 Cf. "Any one of the internal senses, exciting in vigour and perfection, forms a particular species of taste, and enables a man to judge in some one subject of art or genius: but all of the must at once be vigorous, in order to constitute taste in its just extent. This union is necessary, not only for giving it a proper compass, but also for perfecting each of its exertions" (Alexander Gerard, An Essay on Taste to Which is Now Added Part Fourth; With Observation Concerning the Imitative Nature of Poetry, $3^{\text {rd }}$ edition (Edinburgh: J. Bell and W. Creech; London: T. Cadell, 1780), 73.

5 Ibidem. 
Besides, it should be remembered that these emotions come up against our individual disposition, ${ }^{6}$ i.e. sensitivity, various inclinations, tastes, or associations, which in fact makes the aesthetic experience unique. This does not mean, however, that the subjectivity of taste sensations understood in this way entails the relativity of the object's aesthetic value. Of course, if we remain at the level of taste conceived as a kind of sensation, this is indeed the case, but for Gerard, taste is something more. It does not consist only in the accumulation of perceptual material and simple the experiencing of perceived sensual content. In order for taste to gain its proper scope, in order for its judgements to enjoy any intersubjectivity, recognition, and not to provoke opposition from others, it must reach a level of reflexivity. In other words, it must gain support from the sensibility of the heart, as well as from the reason and its judgements.

It is such a sensibility of heart, as fits a man for being easily moved, and for readily catching, as by infection, any passion that a work is fitted to excite. The souls of men are far from being alike susceptible of impressions of this kind. A hard-hearted man can be a spectator of very great distress without feeling any emotion: A man of cruel temper has a malignant joy in producing misery. On the other hand, many are composed of so delicate materials, that the smallest uneasiness of their fellow-creatures excites their pity. A similar variety may be observed, in respect of the other passions. Persons of the former cast will be little affected by the most moving tragedy; those of the latter turn will be interested by a very indifferent one. [...] This diversity in the formation of the heart will produce a considerable diversity, in the sentiments which men receive from works of taste, and in the judgment which they form concerning them. ${ }^{7}$

Moreover, if we are deprived of this sensibility, we cannot enjoy works of art in any way, nor do we have any solid basis to evaluate them reliably. ${ }^{8}$

6 "The degree of force with witch objects strike us, depends much on the prevailing disposition of the mind. Things often affect us deeply, when we are in an humour suited to them, though at another time they would make small impression. The smallest injury may produce fury in a person naturally passionate, or by accident chagrined. When the temper of the mind is such as gives it an habitual turn to one kind of sentiments and affections, it enters into them, whenever they occur, with extraordinary spirit. As they fall in with its predominant bent, no force is required to adapt it to the perception of them; it spontaneously, and even eagerly embraces them, as perfectly conformable to its frame", ibidem, 77.

7 Ibidem, 79.

8 Cf. "Delicacy of passion must be united with vigorous internal senses, in order to give taste its just extent. Where this union takes place, works of genius produce their full effect; and inspire a complicated pleasure. A man receives 
According to Gerard, works of art are calculated for emotional effect, and the creator cares about arousing this effect in the recipient. ${ }^{9}$ Hardness of heart is not synonymous here with disinterestedness or aloofness in the attitude of the recipient. It is a sign of his deficits rather than a predisposition to pass judgements in a tribunal of taste. Sensibility of the heart makes it possible for emotions to accumulate, penetrate one another and intensify. It also becomes a condition for the connections between ideas and emotions that occur in the aesthetic experience. However, without the support of the judgement, even such a defined taste will become distorted or degenerated. Therefore:

The completest union of the internal sense, is not of itself sufficient to form good taste, even though they be attended with the greatest delicacy of passion. They must be aided with judgment, the faculty which distinguishes things different, separates truth from falsehood, and compares together objects and their qualities. Judgment must indeed accompany even their most imperfect exertions. They do not operate, till certain qualities in objects have been perceived, discriminated from other similar, compared, and compound. In all this, judgment is employed: it bears a part in the discernment and production of every form that strikes them. But in assisting their perfect energies, it has a still more extensive influence. Good sense is an indispensable ingredient in true taste, which always implies a quick and accurate perception of things as they really are. That judgment may completely exhibit to internal senses, the beauties and excellences of nature, it measures the amplitude of things, determines their proportions, and traces out their wise construction and beneficial tendency. It uses all the methods which art and science indicate, for discovering those qualities that lie too deep spontaneously to strike the eye. It investigates the laws and causes of the works of nature: it compares and contrast them with the more imperfect works of art; and thus supplies materials from which fancy may produce ideas, and form combinations, that will strongly affect the mental taste. ${ }^{10}$

We will not find such a solution in Alison. Gerard, however, could not do without it. In his desire to guarantee the possibility of passing judgements of reflexive taste, which aspire to objectivity or truthfulness,

adequate perceptions of all their qualities, and by this means has it in his power to allow each its proper weight in determining his judgment concerning the merit of the whole. Delicacy of passion may interest a person so much, that he cannot for some time examine a performance with critical exactness; but it gives him exquisite delight in the mean time, and enables him to pass a just sentence at last" (ibidem, 82).

9 This theme also appears in Alison, for whom this designation of works of art is a characteristic feature.

10 Gerard, An Essay on Taste, 83. 
he could not give up either the immense advantage that comes from introducing reason and its judgement into aesthetic experience. Without introducing into his conception a higher instance in the form of a god that guarantees the correctness of his judgements, he bases taste on the sensibility of the heart and reason, on the natural faculties of the mind. And therefore his theory could in principle do without the support of associative relations. And in fact many of its aspects such is the case. This is because not every type of aesthetic category to which particular detailed tastes correspond is explained by association. Of the three conceptions of beauty presented in An Essay on Taste, only one is explained using association. Gerard, however, recognizes the enormous potential of associationism and at least partially tries to exploit it. ${ }^{11}$ Therefore, we can read here that:

One of the most natural and immediate effects of association is, that, especially when the relation of ideas is close, and their union consequently strong, the transition from one to other is so easy, that the mind takes in a long train of related ideas with no more labour than is requisite for viewing a single perception, and runs over the whole series with such quickness, as to be scarce sensible that it is shifting its objects. ${ }^{12}$

\section{And more:}

Ideas which are thus compounded, or which are, even without composition, only associated, communicate, by the closeness of their relation, their qualities to one another. A perception, by being connected with another that is strong, or pleasant, or painful, becomes itself vigorous, agreeable or disagreeable. The parts of complex perceptions are so intimately united, that the generality seldom reflect on their being distinct; and philosophers cannot analyse them without some study and attention. We are accustomed to consider them all as making but one perception; they are all in the mind at once; and therefore we cannot naturally distinguish from what precise part of a complex perception a particular sentiment results, but must ascribe the sentiments arising from any of the parts to the perception in general. When a perception communicates its qualities to another introduced by it, the reason of the phenomenon is obvious from the principles which we have established. The disposition with which the mind contemplated the first, has a degree of firmness which makes force requisite to destroy or change it; the

11 It is worth noting that Gerard isolates a slightly different set of associative relations from Hume's in Treatise or An Inquiry. He distinguishes between simple associations, based on similarity, contrast and tangency, and more complex ones based on habit, coexistence, causality and order. The first edition of An Essay on Taste lacks references to order.

12 Gerard, An Essay on Taste, 155. 
strength of the union which transports the mind easily from one perception to the others, keeps this force from being applied: the disposition, therefore, which first produced, continues while we view the others; and we imagine, by a kind of illusion, that they produced the disposition which, in reality, was brought to the perception of them; and we ascribe to the them qualities which are necessary for its production. ${ }^{13}$

What we have here is a quintessence of associationism by Gerard. The presented process of showing emotions that are appropriate for the perception of some objects to others, which are associated or co-occur with them, becomes an important element of aesthetic experience. The disposition of the mind, to which the successively appearing ideas are suited or not, changes, and thus intensifies their further influence or weakens it. It makes the succession of perceptions no longer distinct, and the coalescence of ideas intensifies the vividness and force of their reception and paves the way to the mind for further ideas and emotions. If we change our perspective for a moment, move away from the analysis of a single process of associating ideas in the mind, and try to grasp the whole complexity of aesthetic experience, we will see an extremely complex phenomenon. For in the mind there will appear many different trains of ideas and accompanying emotions, which a poor copy, an abstract dry description of a single case, will not be able to render. It is true that Gerard does it better than Hume, but the description of the process of aesthetic experience is always secondary to it and always simpler. Even Izabela Łęcka, the heroine of The Doll, whose quoted fragment serves as the basis for this article, taking delight in the beauty of the forest and the associations it evokes, seems puerile in her isolated remarks addressed to Wokulski. And yet her very experience must have been something more perfect, something more complete, uncommunicable, even inexpressible. Something that probably each of us has experienced when communing with the charms of the forest and manifestations of its countless forms. The singing of birds, the smell of undergrowth, the mist floating amidst the grove, sunlight breaking through the trees, perhaps the right company, time and mood. All this merges in the mind into the unity of aesthetic experience, into a kind of totality. All this intensifies the activity of imagination, giving it satisfaction from the effort of adjusting to the perceived object, ${ }^{14}$

13 Ibidem, 157.

14 Cf. "The sources of all the sentiments of taste lay in the mind. The qualities of objects affected, in a certain manner, some principles of human nature, which by their operation, either singly or several in conjunction, produce gratification or disgust. It is the business of philosophical criticism, to investigate these principles: 
arouses associations, and is connected with something. That is what Gerard wants to give us an account of. It is this experience that he tries to break down into simpler elements. To do this he needed the seven inner senses, the associative links of imagination, the sensibility of the heart, and even reason. The very same idea must have guided Alison, on whom the forest must also have made a similar impression. His imagination was probably equally sensitive and equally susceptible to the charms described.

\section{The autonomy of aesthetic experience}

By aesthetic taste, Alison means the capacity of the human mind through which we perceive and find pleasure in all that is beautiful and sublime in objects of nature and works of art. These qualities, ${ }^{15}$ as this is how Alison expresses beauty and sublimity, are connected with a specific kind of emotion of taste. The latter are distinguished from the emotion of pleasures, arising under the influence of sensory perceptions, sensations, or even memories. He divides these qualities in accordance with their nature into emotions of beauty and sublimity. He believes that they are spread over almost all kinds of objects of human cognition and constitute one of the most extensive sources of our aesthetic delight. At the same time,

many of them have been pointed out in the course of our enquiry. Simplicity, for instance, occasions easiness of conception; novelty or variety, an effort to conceive; amplitude, an expansion of soul. This takes place in every individual, in numberless cases; he is therefore certain from his own experience, that it is conformable to the constitution of his nature. It is likewise to every man, matter of experience, that some of these modes of conception are ordinarily pleasant, and other ordinarily painful" (ibidem, 260). Thus, referring to the classical conception derived from Aristotle, according to which the ease of capturing things gives moderate pleasure, while a certain effort of imagination leads to an increase in the intensity of this emotion, Gerard can determine precisely which of the characteristics e.g. of beautiful objects contributes most to its arousal.

15 This is important because the understanding of beauty or sublimity as concrete qualities places Alison's view closer to the conception of Edmund Burke with his catalogue of aesthetic qualities than to Hume, for whom beauty is an emotion and not any quality of a thing. Alison adds that these qualities evoke their proper emotions: beauty and sublimity, but he does not give up talking about the real or actual beauty and sublimity of objects. Apparently, he does not see this as something that contradicts the conviction that in every aesthetic experience there are some associations involved and every sensual quality can acquire an aesthetic value. 
however, he points out that these qualities require thorough investigation. These, he believes, have not yet been adequately addressed:

These Qualities, however - as we read in the first essay - though so important to human happiness, are not the objects of immediate observation; and in the attempt to investigate them, various circumstances unite to perplex our research. They are often obscured under the number of qualities with which they are accidentally combined: They result often from peculiar combinations of the qualities of objects, or the relation of certain parts of objects to each other: They are still oftener, perhaps, dependent upon the state of our own minds, and vary in their effects with the dispositions in which they happen to be observed. In all cases, while we feel the Emotions they excite, we are ignorant of the causes by which they are produced; and when we seek to discover them, we have no other method of discovery, than that varied and patient EXPERIMENT, by which, amid these complicated circumstances, we may gradually ascertain the peculiar qualities which, by the CONSTITUTION of our NATURE, are permanently connected with the Emotions we feel. ${ }^{16}$

It turns out then, that such a study is not simple. When observing the qualities that interest us, we can see the addition of emotions aroused by the objects that co-occur in a given experience, their mutual sensual or emotional relations or various circumstances of their perception and, moreover, they are conditioned by our momentary disposition of mind and, most importantly, by the constitution of our nature. This latter piece of information should, it seems, arouse our greatest interest. This kind of conditioning, as I mentioned in my remarks on Hume, often leads to the implicit assumption that there is, by some secret power, a fixed connection between concrete qualities of the sensory world and our emotional reactions to them. ${ }^{17}$ For Alison, it will additionally be connected with the

16 Archibald Alison, Essays on the Nature and Principles of Taste (Edinburgh: printed for J.J.G. and G. Robinson; London: Bell and Bradfute, 1790), viii.

17 This may also be the reason not to take seriously the claims of many commentators on Alison's aesthetic considerations about his alleged relativism in the field of aesthetic qualities. The reader may find representations of various aspects of Alison's aesthetic theory in some recent, but also classic general studies of eighteenth-century aesthetics. See Paul Guyer, A History of Modern Aesthetics. Volume 1: The Eighteenth Century (Cambridge: Cambridge University Press, 2014); Samuel Monk, The Sublime: A Study of Critical Theories in XVIII-Century England (Michigan, Ann Arbor: University of Michigan Press, 1960); Walter Hipple, The Beautiful, the Sublime, and the Picturesque in Eighteenth-Century British Aesthetic Theory (Carbondale, 1957); George Dickie, The Century of Taste. The Philosophical Odyssey of Taste in the Eighteenth Century (Oxford-New York: Oxford University Press, 1996) and Peter Kivy, The Seventh Sense. A Study of Francis Hutcheson's 
individual character of our sensibility, the current degree of development of our aesthetic taste and the inclination of our mind to a certain kind of emotions.

The passage cited above provides an interesting perspective on research conducted through experimentation. Alison follows the spirit of the age and, like his two predecessors, postulates actions based on detailed observations made under controlled conditions and amenable to generalization. Their repeatability and verifiability are supposed to ensure the objectivity of the results obtained in this way. Clearly, once again as in the case of the predecessors, no such research was conducted and the method used to solve the problems turned out to be mostly introspective. Anyway, none of the three thinkers discussed here realized their demands in this regard. Each one of them, while limiting themselves to outlining a certain research plan, left its implementation to others. And also each one of them, by generalizing their own experience, while emphasizing the aspect of aesthetic experience that interested them, ultimately limited or distorted its general character.

In order to understand how Alison exhibited the nature of aesthetic experience to himself, we will need to explain the nature of the qualities that elicit emotions of taste and the faculty by which we experience them, i.e. the imagination. Essay one is structured to present the above issues. It succeeded in this only partially. It is difficult to expect an amateur aesthete to paint the nature of imagination in its full glory. Especially after the way Hume did it in Treatise. However, he pointed out the specific way in which it functions, which constitutes aesthetic experience. And that, I think, is quite a lot. Let us reconstruct the most important elements of his reasoning.

Alison comments that those who regarded aesthetic experience as a simple emotion have gone astray. He observed that all the theories of that time "have uniformly taken for granted the Simplicity of this Emotion; that they have considered it as an Emotion too plain, and too commonly felt, to admit of any Analysis; that they have as uniformly, therefore, referred it to some one Principle or Law of the Human Mind; and that the Discovery

Aesthetics and Its Influence in Eighteenth-Century Britain (New York: Burt Franklin \& Co., 1976). Against this backdrop, Steven A. Jauss's extremely interesting and detailed article stands out, not only through a fair presentation of Alison's point of view, but also curbing the critical inclinations and scoring the rather hastily expressed judgements of several of his prominent professional colleagues. It is hard to disagree with his comments. See Steven A. Jauss, "Associationism and Taste Theory in Archibald Alison's Essays", The Journal of Aesthetics and Art Criticism 64, 4 (Fall 2006): 415-428. 
of that one Principle was the essential key by which all the Pleasures of Taste were to be resolved." 18 In the second edition he even expands his accusations and raises them against two types of theories popular of the time. The first group consists of conceptions that assume the existence of the aesthetic taste understood as a kind of internal sense (or senses as understood by Gerard), most often independent of imagination and reason (it was also the subject of Burke's attacks) and responsible for perceiving, feeling, and judging the value of objects (sometimes also human actions). Alison enumerates William Hogarth, Johann Joachim Winckelmann and, with some uncertainty, Joshua Reynolds among its representatives. However, he certainly omits from the submitted list the most important addressees of the accusations, namely the aforementioned Shaftesbury and Hutcheson. The second group consists of conceptions in which the central idea is the belief that there are cognizable principles (or principle, as in the allegations of the $1^{\text {st }}$ edition of Essays) that determine how the mind is moved. The experience of various aesthetic phenomena is explained here by more general laws of our intellectual or moral constitution. ${ }^{19}$ Among the representatives of this group Alison enumerates Denis Diderot and, interestingly, Hume, whom he certainly included because of his notion of beauty identified with utility. Although in Of the Standard of Taste we can find more than ten other principles that define aesthetic phenomena, this does not mean that Hume should be treated only as a representative of the second group. Apparently, Alison does not see him as a thinker to whom the views of the "school of the inner sense" are close, although I admit that this is not explicitly highlighted in his work. He speaks too often of a sense of beauty in objects and human actions, and of a kind of common sense that allows us to judge accurately in matters of taste, for us to overlook that he finds a similar solution intriguing. Alison did not know what to do with Gerard so he did not mention him at all. We would also have a problem with an unambiguous classification of this theorist of taste, because his aesthetic conception, being a transitional one, contains both a considerable number of assumptions characteristic for the theories of the inner sense and many solutions used by thinkers convinced of the

18 Archibald Alison, Essays on the Nature and Principles of Taste, Vol. 1 (Edinburgh: printed for Bell \& Bradfute, and Arch. Constable and Co.; Edinburgh: F.C. and J. Rivington; London: Constable, Hunter, Park, and Hunter, 1811), xviii. See also: "It seemed to me that the SIMPLICITY OF THE EMOTION OF TASTE, was a Principle much too hastily adopted; and that the consequences which followed from it [...] were very little reconcilable with the most common experience of Human Feeling"' (Alison, Essays on the Nature and Principles of Taste, 1811, XXI).

19 Ibidem, XIX-XX. 
existence of laws that define the broadly understood functioning of mind, including the principles of aesthetic taste. As such, his conception may appear incoherent, to some even untenable. However, would Alison, who was sufficiently familiar with the aesthetic literature of the time, as well as traditional literature, avoid similar accusations? Would he succeed in his intended project to a greater extent than his learned colleagues? It seems that by consciously embarking on an untrodden path, he is charting a new direction for research. He dreams that associationism can be consistently developed and used as an explanation for the most important mechanism of the creation and course of aesthetic experience. He plans the whole venture and charts the next stages. He proposes to begin by analyzing the effects that occur in the mind of the viewer when he experiences the Emotion of Beauty or the Sublime. So he begins his rationale by presenting the basic elements of the aesthetic situation, that is, in the first place, the primal emotion, a kind of primal reaction to a certain quality of the object, in order to then move on to aesthetic feelings in the proper sense of the word.

I shall endeavour to shew, that this effect is very different from the determination of SENSE; that it is not in fact a Simple, but a Complex Emotion; that it involves in all cases, $1^{\text {st }}$, the production of some Simple Emotion, or the exercise of some moral Affection; and 2dly, the consequent Excitement of a peculiar Exercise of the Imagination; that these concomitant effects are distinguishable, and very often distinguished in our experience; and that the peculiar pleasure of the BEAUTIFUL or the SUBLIME is only felt when these two effects are conjoined, and the Complex Emotion produced. ${ }^{20}$

Aesthetic experience is thus based on a kind of two-stage character of the experiences that constitute it. At first, the recipient is overcome with an emotion which is simple in its nature, not reducible to other emotions associated with sensory perception, different from the emotion of taste proper and necessarily preceding it:

There is undoubtedly a very great difference between the Emotion of Taste, and any Simple Emotion, as of Cheerfulness, Tenderness, Melancholy, Solemnity, Elevation, Terror, \& c. as such emotions are frequently felt, without any sentiment of Beauty or Sublimity; but there is no case, I believe, where the Emotions of Taste are felt, without the previous production of some such Simple Emotion. It is often indeed difficult to say, what is the quality in the object which produces the Emotion of Beauty; and it is sometimes difficult, in the case of complex objects, when different qualities unite in the production of Emotion, to define the exact nature of that Emotion which we feel; but

20 Ibidem, XXII-XXIII. 
whether the general impression we receive is that of Gaiety, or Tenderness, or Melancholy, or Solemnity, or Elevation, or Terror, \& c. we have never any difficulty of determining: and so strong is our conviction of the dependence of the Emotions of Taste upon some such previous Simple Emotion, that whenever we endeavour to explain the Beauty or Sublimity of any object, we uniformly proceed by pointing out the interesting or affecting quality in it, which is fitted to produce this previous emotion. It is not only impossible for us to imagine an object of Taste, that is not an object of Emotion; but it is impossible to describe any such object, without resting the description upon that quality, or those qualities in it, which are productive of simple emotion. $^{21}$

Simple emotions, though of a non-aesthetic character, convey the particular nature of the object perceived, for example: a melancholic mood of the scenery, the solemn character of a speech, the sad tone of utterances, etc. But when these things are just as we perceive them, i.e., truly melancholic, solemn, sad, etc., and consequently beautiful or sublime, ${ }^{22}$ they are then capable of arousing a simple emotion or moral affection, and later an aesthetic train of images united in respect of emotions. They are then able, without doing so directly, to bring about an exercise of imagination. ${ }^{23}$

21 Ibidem, 58-59.

22 Alison, like Burke, remains with the two chief aesthetic categories, so that all simple emotions aroused by capable objects must be recognized as instances of either of them. At the same time, he adds that objects can be sublime and beautiful only when they arouse a simple or moral affection, and later an exercise of imagination. The way Alison speaks about beauty and the sublime makes it difficult to clearly define his position on this issue. In the text we find firm statements that no quality by itself is of an aesthetic nature, although thanks to associations each quality may gain this feature or ability to arouse proper aesthetic feelings. On the other hand, there are many expressions of beauty and sublimity as real, actual, and the question of the planned next essay in which the question of the standard of taste was to be one of the main ones. According to Alison, taste can be developed. All this may indicate an emphasis on the individuality of experiences of beauty and sublimity, but it does not necessarily relativize their value. The necessary participation of associative relations in aesthetic experience does not prejudge its total relativity. The possibility of relating any sensory quality to any other quality does not do this either. Looking at it from a different perspective, one might wonder what the purpose of taste education actually is, if everything can please us. It cannot be just the length of the experience? Their quality still comes at a price.

23 Actually, what is meant here is the fact that successive ideas appear in the imagination which are consistent with the preceding ones in emotional terms and are associated with them through sensory similarity. In other words, an aesthetic train of ideas is aroused and runs in it. We can also suppose that by effort of imagination we should understand the awareness of the effort that we put in capturing some element of a work of art, e.g. the relation of its parts to the 
Trains of thoughts and images then begin to run through the imagination. Only these, apparently without the participation of simple emotions or moral affections that arouse them, constitute the experience of the "peculiar pleasure of the BEAUTIFUL or the SUBLIME". Only then are we dealing with a complex emotion, in which individual (also simple) emotions that accompany the successive images and thoughts of the aroused train of thoughts and images come to the fore, which harmonize with the general character of the emotion that flows from the perception of the object. The whole aesthetic trains of ideas that comprises them is then characterized by this emotion. It is a response to that which dominates the nature of the quality of the perceived object:

In the case of those trains of thought, on the contrary, which are suggested by objects either of Sublimity or Beauty, I apprehend it will be found, that they are in all cases composed of ideas capable of exciting some affection or emotion; and that not only the whole succession is accompanied with that peculiar emotion, which we call the Emotion of Beauty or Sublimity, but that every individual idea of such a succession is in itself productive of some simple Emotion or other. Thus the ideas suggested by the scenery of Spring, are ideas productive of emotions of Cheerfulness, of Gladness, and of Tenderness. The images suggested by the prospect of ruins, are images belonging to Pity, to Melancholy, and to Admiration. The ideas in the same manner awakened by the view of the ocean in a storm, are ideas of Power, of Majesty, and of Terror. In every case where the emotions of Taste are

whole. The more complex the work is, the more difficult this relation is to grasp. The effort made, however, gives a kind of satisfaction, if only from the sense of one's own ability to understand and penetrate the work. Cf. the following passage: "When any object, either of sublimity or beauty, is presented to the mind, I believe every man is conscious of a train of thought being immediately awakened in his imagination, analogous to the character or expression of the original object. The simple perception of the object, we frequently find, is insufficient to excite these emotions, unless it is accompanied with this operation of mind, unless, according to common expression, our imagination is seized, and our fancy busied in the pursuit of all those trains of thought, which are allied to this character of expression. Thus, when we feel either the beauty or sublimity of natural scenery - the gay lustre of a morning in spring, or the mild radiance of a summer evening, the savage majesty of a wintry storm, or the wild magnificence of a tempestuous ocean- we are conscious of a variety of images in our minds, very different from those which the objects themselves can present to the eye. Trains of pleasing or of solemn thought arise spontaneously within our minds; our hearts swell with emotions, of which the objects before us seem to afford no adequate cause; and we are never so much satiated with delight, as when, in recalling our attention, we are unable to trace either the progress or the connexion of those thoughts, which have passed with so much rapidity through our imagination" (Alison, Essays on the Nature and Principles of Taste, 1790, 2-3). 
felt, I conceive it will be found, that the train of thought which is excited, is distinguished by some character of emotion, and that it is by this means distinguished from our common or ordinary successions of thought. To prevent a very tedious and unnecessary circumlocution, such ideas may perhaps, without any impropriety, be termed Ideas of Emotion; and I shall beg leave therefore to use the expression in this sense. ${ }^{24}$

Thus, each idea of an aesthetic train induces a simple emotion that is in harmony with the others. How does that happen? How is it possible that trains of ideas of emotion are so unified? Why does one idea follow another? The answer lies in associative relations. ${ }^{25}$

For aesthetic experience to take place in the right way, it is not enough that a train of images and accompanying feelings pass through imagination. This happens almost all the time - there is nothing unusual about it. No particularly strong emotions that move us arise. Alison argues, however, that there is a specific kind of aesthetic train that differs from others in its unified emotional character and its ability to arouse feelings. However, for the train of ideas of emotions to exist at all and fulfil its role - to give us aesthetic satisfaction - a specifically aesthetic attitude of the recipient towards works of art or objects of nature is necessary. It is a well-known disinterested attitude, which was quite widespread at that time in various versions in Britain - a specific attitude towards the appearing forms of objects:

That state of mind, every man must have felt, is most favorable to the emotions of taste, in which the imagination is free and unembarrassed, or in which the attention is so little occupied by any private or particular object of thought,

24 Ibidem, 52-53.

25 Cf. the following passage: "In those trains, on the contrary, which are suggested by objects of Sublimity or Beauty, however slight the connection between individual thoughts may be, I believe it will be found, that there is always some general principle of connection which pervades the whole, and gives them some certain and definite character. They are either gay, or pathetic, or melancholy, or solemn, or awful, or elevating, \& c. according to the nature of the emotion which is first excited. Thus the prospect of a serene evening in summer, produces first an emotion of peacefulness and tranquillity, and then suggests a variety of images corresponding to this primary impression. The sight of a torrent, or of a storm, in the same manner, impresses us first with sentiments of awe, or solemnity, or terror, and then awakens in our minds a series of conceptions allied to this peculiar emotion. Whatever may be the character of the original emotion, the images which succeed seem all to have a relation to this character; and if we trace them back, we shall discover not only a connection between the individual thoughts of the train, but also a general relation among the whole, and a conformity to that peculiar emotion which first excited them" (ibidem, 54-55). 
as to leave us open to all the impressions which the objects that are before us can create. It is upon the vacant and the unemployed, accordingly, that the objects of taste make the strongest impression. It is in such hours alone, that we turn to the compositions of music, or of poetry, for amusement. The seasons of care, of grief, or of business, have other occupations, and destroy, for the time at least, our sensibility to the beautiful or the sublime, in the same proportion that they produce a state of mind unfavorable to the indulgence of imagination. ${ }^{26}$

Taking such a disinterested attitude, together with a sense of freedom that accompanies imagination, thus becomes a condition of aesthetic experience. The imagination, unfettered in its actions and reactions, in a spontaneous response to subsequent images of the aesthetic train, gives birth to subsequent ideas. It allows them, in a sense, to resound in our consciousness, while at the same time it - the power of imagination - from the very moment it mechanically turns to the reservoir of memory, selects, changes, combines in order to paint for us what, from the emotional point of view, perfectly harmonizes with the prevailing emotion, and from the sensual point of view with the perceived quality of objects. It is therefore, in a sense, the object that sets the ultimate tone for aesthetic experience. It all starts with capturing its quality. The object imposes itself on the imagination with its qualities and incites it to extract the corresponding ideas from itself, as long as they are connected by a relation of similarity, as long as the emotions are synchronized. In an uncrowded imagination it is easier to stir up feelings. It is also easier to narrow down the circle of objects of interest and, based solely on their quality, to spark further ideas. Let imagination run wild and let it make memory resources available to our delight. It is a specific kind of disinterestedness, because it is not about suspending emotions or giving up sensual pleasure. Nor is it contemplation of pure form, or harmony of affects. And yet Alison does not forget that education, which he repeatedly refers to, customs, habits, individual tastes, and finally private associations, are not without influence on the train of ideas of emotion discussed here. Youth, with all its immersion in sensuality and its inherent vivid imagination, is perfect for losing oneself in such an experience. In turn, the influence of judgement, reflection, repeated study of the object, analysis of it, and, in general, any subjecting of it to the judgements of reason, criticism, or estimation of its value, nullify the whole enterprise. The atmosphere is gone, the emotion is gone. Something else, something non-aesthetic, catches our attention. The flow of imagination is stopped. And until a certain inner peace is

26 Ibidem, 6. 
restored, until we stop giving our imagination the next ordinary train of thoughts, we will not be ready for a new aesthetic experience. However, not everyone can experience them in an equally intense, equally vivid or, so to say, equally valuable and true way. The natural constitution, as much as the momentary disposition of the mind, is different in each of us, let alone the content of our experiences. With such different professions, interests, education, etc. as we observe in every society, it is difficult for us to have the same perceptual material. However, Alison does not see this as a problem or a threat to his conception. He is convinced that every man is able to recognize whether his own or someone else's admiration for the beauty of an object is dictated by associations that are natural to that object, or whether it comes from some private associations which, though incommunicable and personal, nevertheless play their own aesthetic role. The difference in material is therefore less important here. Imagination has the ability of generating ideas from itself, which are similar to the preceding ones in any qualitative respect. The important thing is that it does it, and not by what means. Thus on the one hand there may be private associations, and on the other national ones; stronger ones, which were born in our youth, and weaker ones, born out of chance; based on one or on many classes of sensory qualities. Ultimately, the most important thing is that the exercise of fancy increases, because through it the emotion of beauty or the sublime also increases. This is where such an important role of our memories in aesthetic experience comes from. Not all of course, but the significant ones, those whose recollection in the memory evokes strong emotions and united emotional trains of ideas. The emotions associated with such a memory outweigh those aroused by the currently perceived object. Imagination has at its disposal an enormous number of combinations of both aesthetic and non-aesthetic trains. And all that is born out of experience. The family home, the neighborhood, everyday objects and all sorts of circumstances. How many sources of aesthetic content? The more associations, the easier it is for the imagination to present another idea in an aesthetic train. The longer these trains, the longer the exercise of imagination and the stronger the feeling of beauty or sublimity. This connection made by Alison was very simple. Therefore, a factor that has an impact on taste lies in the richness of sensory experience. Early exposure to the art of antiquity greatly diversifies how we perceive it later, just as familiarity with literature allows you to enjoy each successive masterpiece. Without previously collected perceptual material, the associations will not be established, and without appropriate sensibility and taste, those that have the appropriate aesthetic potential will remain unnoticed. 
We differ in taste, but we have a need to share our aesthetic experience with another person. We are able to find out the reasons, or concrete sensory experiences in this case, why a person close to us reacts in a certain way to a perceived object. We understand how the absence of an association deprives us of the pleasure of enjoying a particular work with others. It cannot surprise us, then, that, conscious of differences in upbringing, education, and career, mentioning only the determinants of our experience, we do not expect to find a friend in every person. We cannot share our feelings with everyone. Therefore, when Łęcka, enraptured by the beauty of the forest, draws Wokulski's attention to the rush of her thoughts and the associations that she has, she is aware only of the inexpressible, as Alison says - of what runs through her imagination. How she wished this merchant could become someone who saw the world as she did, who experienced it the same way, so that he could see the same similarities, so that his imagination conjured up the same images. She is well aware of the gap that separates them. His background, social status, occupation, practical sense, daily chores, and planned interests, not to mention his red frostbitten hands, totally cancel out the chance of sharing experiences. When asking a desperate question - "Do you see it as I do?" she would like to hear an affirmative answer. It would mean that the prospect of living with such a repulsive character, as Wokulski appeared to her, would disappear, not only because of the wealth he had acquired, but also because of the commonness of their experiences. She clung to this idea and hoped to build a new relationship on it. Meanwhile, the hard-headed Wokulski was unable to share her affections. Just as when, through jealousy, he was unable to share her enthusiasm about Ernesto Rossi. Then, he did not share her emotions either. And yet it is possible for two people to derive satisfaction from a shared aesthetic experience. In each of them it is based on different ideas of emotion, but the fact that they are both aware of this aesthetic commonness of experience becomes a source of additional satisfaction. We enjoy this commonness while being fully aware of the difference in the ideas that constitute it. How many relationships have been saved thanks to it, or how many romances have been started?

In Alison's conception of aesthetics we see an increase in the importance of experiencing the aesthetic experience itself. This happens at the expense of the correctness of judgements of taste; these are given far less attention. Alison makes it clear about what influences our aesthetic sensibilities and indicates to whom they are given in a limited range. It is clear that the developed taste gains access to satisfaction of a higher kind than that which available to a common person. Beauty and sublimity can 
be experienced by all. If it were otherwise, as Alison claims, it would be very unfair. Everyone can experience them, the only question is what shape of aesthetic experience they will assume. This aesthetic experience, understood above all as an autonomous train of ideas, will be longer or shorter, more or less intense. Based on some associations, on some simple emotion, on some moral affection. Alison does without raising the question of the propriety of judgements of taste. It does not matter that it is more important for young people that their imagination was set in motion than why it was done. In the end, what matters here is survival. The problem of the similarity of experiences and judgements of different people ceases to be relevant. It is not about belonging to a group of owners of developed taste, but about one's own experience. It is its quality or value that becomes the reason to work on taste. Thus, Alison no longer belongs spiritually to the eighteenth-century aesthetic tradition and his approach heralds changes, and certainly a shift in highlighting subsequent aesthetic concepts.

The introduction to the second essay of 1811 reads:

But although the qualities of matter are in themselves incapable of producing emotion, or the exercise of any affection, yet it is obvious that they may produce this effect, from their association with other qualities; and as being either the signs or expressions of such qualities as are fitted by the constitution of our nature to produce Emotion. Thus, in the human body, particular forms or colours are the signs of particular passions or affections. In works of art, particular forms are the signs of Dexterity, of Taste, of Convenience, of Utility. In the works of nature, particular sounds and colours, \& c. are the signs of Peace, or Danger, or Plenty, or Desolation, \& c. In such cases, the constant connection we discover between the sign and the thing signified, between the material quality and the quality productive of Emotion, renders at last the one expressive to us of the other, and very often disposes us to attribute to the sign, that effect which is produced only by the quality signified. ${ }^{27}$

However, the second edition of the essays is not just about minor cosmetic improvements. Indeed, it brought some changes to the presented position. The view that the beauty and sublimity of objects are based not on their material qualities, but on what they mean or express to us, has been maintained. In other words "qualities of matter are not to be considered as sublime or beautiful in themselves, but as being the SIGNS or EXPRESSIONS of such qualities, as, by the constitution of our nature, are fitted to produce pleasing or interesting emotion." ${ }^{28}$ Alison specified his point. He

27 Alison, Essays on the Nature and Principles of Taste, 1811, 178-179.

28 Ibidem, 416. 
argued that, in addition to all the trains of ideas necessary to the existence of aesthetic experience, aroused by the qualities of objects naturally suited to such a stirring of emotions, a second kind of association is necessary. ${ }^{29}$ It is based on the fact that the perceived quality of an object must imply or express qualities of mind. This quality must be a sign or expression of the powers or capacities of mind or those affections or dispositions of mind which suit us personally. If it is of this nature, it will "produce in us immediately the peculiar emotions which, by the laws of our nature, the mental qualities are fitted to produce." ${ }^{30}$ Qualities, however, can be signs or expressions of qualities of mind for us in another way, namely indirectly. It is experience that teaches us about them. It points to those qualities that we recognize as means or instruments that arouse emotions that are close to us or affections of mind. Analogy or similarity is another source of them. They can also be derived from associations. Not just the private ones, but as Alison says, the ones in the proper sense of the word: "[...] when by means of education, of fortune, or of accident, material objects are connected with pleasing or interesting qualities of mind; and from this connection become forever afterwards expressive of them." 31 Alison thus became the most radical proponent of the use of associative relations in aesthetics.

\section{Conclusions}

This article was not intended to reconstruct and explain the entire development of associationism in British aesthetics in the $18^{\text {th }}$ century. Nor did I intend to point out all the sources of Alison's associationism. The objectives of the article were far more modest. I think I have succeeded in showing how Hume's idea of using associative relations of imagination to explain the nature of cognitive processes was first used in part by Gerard, and then in full by Alison, to explain the nature of aesthetic experience. The adaptation of the main idea was not immediate. Hume himself did not use it as he should have either. Or at least no information about it has survived. Gerard had more luck. He noticed the potential of associationism and, in spite of the partly irreconcilable solutions adopted in his aesthetic conception straight from the "school of the inner sense", he used it to ex-

29 George Dickie calls it 'inferential association'. See Dickie, The Century of Taste, 56.

30 Alison, Essays on the Nature and Principles of Taste, 1811, 419.

31 Ibidem, 421. 
plain some elements of aesthetic experience. He went into more detail about taste and how it works than his great predecessor. He emphasized the role of the disposition of the mind, the accumulation of emotions, the sensibility of the heart and finally reason. In fact, it was only the latter that Alison did not have any role for in his theory of taste. All his judgements were superfluous to him; as we remember, they even annihilated aesthetic experience. They stopped the flow of imagination.

He differed from Gerard in this respect, but his exercise of imagination, disposition of mind, coalescence of ideas, or the accumulation of emotions that he read in An Essay on Taste certainly suited him. Their knowledge results in the clarification of one's own original position. Indeed, it is an untrodden path - it was charted by Hume, but it is Alison who walks down this path alone. He leaves behind a rather remarkable project. A consistently developed associationist conception implemented into aesthetic experience. In fact, associative relations together with their associated ideas and emotions turn out to be the main content of this experience. In a certain sense, although the aesthetic trains of ideas of emotion created from them depend on certain qualities of the object, they ultimately prevail over it, captivating the subject with the leading emotion of aesthetic experience and the ideas that follow. The trains then persist independently of further perception of the object by the force of association and emotional unification. Aesthetic experience becomes autonomous. In fact, imagination becomes autonomous - it reaches into the resources of memory and recalls whatever it wants in its spontaneity, as long as the flow of imagination is preserved.

\section{Bibliography}

Archibald Alison. 1790. Essays on the Nature and Principles of Taste. Edinburgh: printed for J.J.G. and G. Robinson; London: Bell and Bradfute.

Archibald Alison. 1811. Essays on the Nature and Principles of Taste, Vol. 1. Edinburgh: printed for Bell \& Bradfute, and Arch. Constable and Co.; London: F.C. and J. Rivington, and Constable, Hunter, Park, and Hunter.

Dickie George. 1996. The Century of Taste. The Philosophical Odyssey of Taste in the Eighteenth Century. Oxford-New York: Oxford University Press.

Gerard Alexander. 1780. An Essay on Taste to Which is Now Added Part Fourth; With Observation Concerning the imitative Nature of Poetry. Edinburgh: J. Bell, and W. Creech; London: T. Cadell.

Guyer Paul. 2014. A History of Modern Aesthetics. Volume 1: The Eighteenth Century. Cambridge: Cambridge University Press. 
Hipple Walter. 1957. The Beautiful, the Sublime, and the Picturesque in Eighteenth-Century British Aesthetic Theory. Carbondale.

Hume David. 1854. "An Inquiry Concerning Human Understanding". In: David Hume, The Philosophical Works of David Hume. Including All the Essays, and Exhibiting the More Important Alterations and Corrections in the Successive Editions Published by the Author. In Four Volumes. Vol. 4. Boston: Little, Brown and Company; Edinburgh: Adam and Charles Black.

Hume David. 1896. A Treatise of Human Nature, reprinted from the original edition in three volumes and edited, with an analytical index, by L. A. Selby-Bigge. Oxford: The Clarendon Press.

Jauss Steven A. 2006. "Associationism and Taste Theory in Archibald Alison's Essays". The Journal of Aesthetics and Art Criticism 64, 4: 415-428.

Kivy Peter. 1976. The Seventh Sense. A Study of Francis Hutcheson's Aesthetics and Its Influence in Eighteenth-Century Britain. New York: Burt Franklin \& Co.

Monk Samuel. 1960. The Sublime: A Study of Critical Theories in XVIII-Century England. Michigan, Ann Arbor: University of Michigan Press.

Morawski Stefan. 1961. Studia z historii myśli estetycznej XVIII i XIX w. Warszawa: PWN.

Pazura Stanisław. 1981. De gustibus. Rozważania nad dziejami pojęcia smaku estetycznego. Warszawa: PWN.

Prus Bolesław. 1966. The Doll, translated by David Welsh, introduction St. Barańczak. Central European University Press.

\section{Summary}

The present article is devoted to aesthetic experience as conceived by Archibald Alison. It reconstructs the associationist sources of his views in the form of selected issues from the aesthetics of D. Hume and A. Gerard. In the case of the former, three types of beauty and the general characteristics of experiencing them are recalled. In the case of the latter, a general view of the nature of aesthetic experience is presented, including the role of internal senses, feelings, their accumulation and associative relations. Alison's conception of autonomous aesthetic experience is laid out based both on the first edition of his works and on subsequent editions, which include quite substantial revisions. Discussed in detail here are the issues of simple emotion and the aesthetic train of ideas, which together constitute an autonomous aesthetic experience. Also, the article provides an explanation of the difference between emotions of pleasure and emotions of taste. Moreover, it outlines the social resonance of aesthetic taste and its manifestations.

Keywords: Alexander Gerard, David Hume, Archibald Alison, Eighteenth-Century British aesthetics, aesthetics taste, imagination, trains of ideas, trains of emotion, associationism 